\title{
O MATERIAL PARTICULADO E O DIREITO À QUALIDADE DO AR DAS GERAÇÕES PRESENTES E FUTURAS
}

\author{
THE PARTICULATE MATTER AND THE RIGHT TO AIR QUALITY OF THE \\ PRESENT AND FUTURE GENERATIONS
}

\author{
Haide Maria HUPFFER* \\ André Rafael WEYERMÜLLER ${ }^{* *}$ \\ Darlan Daniel ALVES ${ }^{* * *}$
}

RESUMO:

Este estudo analisa a legislação ambiental braseira, no que trata da proteção da qualidade do ar, considerando os padrões de Material Particulado, seu monitoramento e suas especificações e compara-a com a legislação norte-americana, no que esta dispõe acerca dos mesmos parâmetros. Inicialmente é realizada uma reflexão sobre a responsabilidade da geração atual para com as gerações futuras quanto à qualidade do ar atmosférico que se deixará de legado para os futuros habitantes. Além disso, salienta-se a importância dos estudos ambientais como base para análise e atualização legislativa. Foi possível concluir que a legislação norteamericana apresenta grande evolução desde seu início em 1971 e, atualmente, pode-se dizer que está à frente da legislação brasileira no que diz respeito aos parâmetros monitorados, sendo esses condizentes com os resultados de pesquisas científicas, especialmente em relação ao material particulado fino $\left(\mathrm{MP}_{2,5}\right)$.

\section{PALAVRAS-CHAVE:}

Qualidade do ar; material particulado; poluição; legislação ambiental; princípio da precaução; princípio da equidade intergeracional.

\footnotetext{
* Docente no Curso de Direito, Docente e Pesquisadora no Programa de Qualidade Ambiental da Universidade Feevale (Novo Hamburgo/RS/Brasil). E-mail: haide@ feevale.br

${ }^{* *}$ Docente e Pesquisador no Programa de Pós-Graduação em Qualidade Ambiental da Universidade Feevale (Novo Hamburgo/RS/Brasil). E-mail: andrerw@ feevale.br

*** Mestrando do Programa de Qualidade Ambiental da Universidade Feevale (Novo Hamburgo/RS/Brasil). Email: darlandaniel@gmail.com
} 


\section{O MATERIAL PARTICULADO E O DIREITO À QUALIDADE DO AR [...]}

ABSTRACT:

This study analyzes Brazilian environmental law, for what concerns the protection of air quality, considering the standard of Particulate Matter, its monitoring and specifications and compares it to the North American law, for what concerns its provisions about the same parameters. Initially, a reflection on the responsibility of the present generation to future generations, regarding the quality of atmospheric air that will be left for future residents, is performed. Besides, the importance of environmental studies as a basis for analysis and legislative updates is also emphasized. It was possible to conclude that the North American law has evolved, since its inception in 1971 and currently one can say that it is ahead of Brazilian law for what concerns the monitored parameters, which are consistent with the results of research science, especially in relation to fine particulate matter $\left(\mathrm{PM}_{2,5}\right)$.

\section{KEYWORDS:}

Air quality; particulate matter; pollution; environmental law; precautionary principle; intergenerational equity principle.

\section{INTRODUÇÃO}

Os processos de urbanização e desenvolvimento industrial são os principais responsáveis pela degradação do meio ambiente, que pode ocorrer em função de lançamentos de poluentes na atmosfera, sejam eles sólidos, líquidos ou gasosos, causando efeitos nocivos e alterando desfavoravelmente os solos, as águas e o ar. Considerando-se que a poluição corresponda a qualquer alteração desfavorável das características físicas, químicas e biológicas do meio ambiente, é possível inferir que esta esteja fortemente vinculada aos processos de desenvolvimento com consequências drásticas à sociedade pós-moderna.

Com efeito, pode-se dizer que a toda e qualquer ação humana sobre o meio ambiente estão vinculadas aspectos e impactos ambientais. Entre os impactos ambientais, destacam-se aqueles considerados significativos, ou seja, aqueles que, unitariamente ou em ação conjunta, possam afetar desfavoravelmente a capacidade de suporte do meio ambiente. Portanto, a fim de promover o desenvolvimento sustentado com práticas que minimizem os danos ambientais, a conjugação do Direito Ambiental e da Ética Ambiental poderá aliar-se aos esforços da Ciência para compatibilizar as ações humanas com a capacidade de suporte do meio ambiente, de forma que não ultrapassem seu limite, mas que ocorram de modo a R. Fac. Dir. UFG, v. 40, n.1, p. 188 - 207, jan. / jun. 2016 
preservar a qualidade de vida das gerações presentes e futuras, tendo como base a qualidade ambiental positiva, propícia aos ecossistemas naturais e aos ecossistemas sociais. (MILARÉ, 2013).

Entretanto, o que se percebe em relação à qualidade do ar nos grandes centros urbanos é que a capacidade de suporte do meio ambiente para a poluição atmosférica já foi ultrapassada e, dessa forma, a qualidade do ar nesses locais atingiu níveis considerados prejudiciais à qualidade de vida da população, tornando-o um elemento nocivo à saúde humana e também ao meio ambiente. A poluição do ar em grandes cidades ocorre principalmente por emissões originadas de fontes fixas e móveis, representadas pelas emissões industriais e aquelas resultantes da queima de combustíveis por veículos automotores.

No Brasil, o Poder Público, tendo em vista sua responsabilidade de proteção do meio ambiente, claramente prevista na Constituição Federal de 1988, elaborou diversos diplomas legais que visam à adequação das atividades humanas ao desenvolvimento sustentável, por meio da elaboração de parâmetros de qualidade do ar a serem analisados, bem como de padrões a serem observados. Esses dados devem gerar informações que auxiliem no gerenciamento adequado dos recursos naturais e também sirvam para a elaboração de políticas públicas de proteção ambiental. Entre os principais poluentes do ar destacam-se os aerossóis atmosféricos, presentes nos documentos legais como o parâmetro Material Particulado, que se destaca por ser um dos principais causadores de danos ambientais e que está presente em quantidades elevadas principalmente nos grandes centros urbanos.

Este estudo analisa a legislação ambiental brasileira, regulamentada pelas resoluções do Conselho Nacional do Meio Ambiente (CONAMA), especificamente a norma que dispõe sobre o parâmetro Material Particulado e seus padrões, comparando-a com a legislação ambiental norte-americana, elaborada pela Agência de Proteção Ambiental daquele país (Environment Protection Agency -EPA). Além disso, apresenta a relevância de estudos recentes que tratam sobre a qualidade do ar e dos problemas relacionados, principalmente, com a fração fina do Material Particulado $\left(\mathrm{MP}_{2,5}\right)$, sugerindo que esses estudos devam ser considerados quando da elaboração e atualização das normas que visam à proteção da qualidade do ar.

Para tanto, realiza-se uma discussão inicial sobre o reconhecimento da fundamentalidade do direito ao meio ambiente equilibrado e saudável na perspectiva do 


\section{O MATERIAL PARTICULADO E O DIREITO À QUALIDADE DO AR [...]}

princípio da solidariedade intergeracional e do princípio da dignidade da pessoa humana, partindo da sociedade de risco.

\section{SOLIDARIEDADE INTERGERACIONAL E O DIREITO FUNDAMENTAL À QUALIDADE DO AR}

Os discursos políticos e textos jurídicos da segunda metade do século XX sobre meio ambiente e qualidade de vida se sustentam na preocupação com os hóspedes futuros do planeta (gerações futuras), buscando assegurar uma proteção aos meios naturais desinteressada, no seu melhor nível, com o maior número de opções possíveis e no longo prazo. É a ideia de missão confiada. Ou seja, as gerações presentes são chamadas para atuarem como guardiãs do meio ambiente. Também pode ser compreendida como “obrigações de prudência no sentido lato, apelando à ideia de limite, uma vez que é a ilimitação dos nossos comportamentos que gera a fragilidade" (OST, 1997, p. 215 e 310).

Nessa perspectiva, o reconhecimento de direitos às futuras gerações humanas reforça a ideia de responsabilidade e dever jurídico de "resguardar as condições existenciais das pessoas que virão a habitar o planeta" (SARLET; FENSETERSEIFER, 2011, p. 41). O olhar aqui é sobre o dever de prudência que está em possibilitar para as gerações presentes e futuras o direito de respirar um ar sadio, direito este fundamentado no direito a um meio ambiente ecologicamente equilibrado e no direito à saúde.

Nesse sentido, pode ser lido o imperativo formulado por Jonas (2006, p. 47): “aja de modo a que os efeitos da tua ação sejam compatíveis com a permanência de uma autêntica vida humana sobre a Terra"; ou na expressão negativa do autor: "aja de modo a que os efeitos de tua ação não sejam destrutivos para a possibilidade futura de uma tal vida”. Fica bem claro no imperativo apresentado que as ações e omissões das gerações presentes carregam consigo um potencial destrutivo capaz de colocar em risco a vida humana e as demais formas de vida do planeta Terra em um futuro não muito distante.

Para reforçar tal entendimento, Beck (2007, p. 40-42) indica que esses riscos resultam do que ele chama de catástrofe-premeditada, ou seja, catástrofes decorrentes de riscos globais ecológicos e econômicos anunciados em que a "antecipación de muerte colectiva se convierte en algo cotidiano". Para o autor, os grandes riscos são globais e possuem uma explosividade física e social que afetam a todos, inclusive aos que causam o risco. É nesse sentido que o autor alerta que a "Sociedad del riesgos es una sociedad inasegurable"(BECK, 2007, p. 51). 
Os riscos ecológicos de grande impacto são "democráticos” por não seguirem as linhas de segregação geradas pela desigualdade social. Ou seja, não são os bens que as pessoas usufruem que as tornariam iguais, mas os malefícios ambientais compartilhados e que ameaçam a saúde de todos indistintamente (COUTINHO, 2010). As toxinas e poluentes presentes na água, no ar e nos alimentos desencadeiam danos em efeito bumerangue, que implode o sistema de classes. Torna-se exemplarmente claro o problema da contaminação do ar atmosférico em grandes centros urbanos: todos são afetados. E um equívoco na estipulação de limites de tolerância humana para os poluentes atmosféricos significa danos irreversíveis à saúde e qualidade de vida (BECK, 1992).

Assim, o conceito de risco de Beck (1998, p. 120) é paradigmático no sentido de que a sociedade industrial não previu externamente as situações de perigo do processo de industrialização. Para o autor, os riscos são "el producto histórico, la imagen refleja de las acciones humanas y de suas omisiones, son la modernização del gran desarollo de las fuerzas productivas". Por sua vez, o resultado do excessivo processo de industrialização e da depredação dos recursos naturais faz nascer outra sociedade: a Sociedade de Risco, que passa a incorporar os riscos do desenvolvimento tecnocientífico. O que a caracteriza é o alto grau de incerteza, indeterminação, desconhecimento e intangibilidade dos novos riscos em que a sociedade é colocada "simultaneamente numa relação de responsabilidade social e jurídica" e na qual a população não mais se divide em classes sociais, mas em relação ao risco social a que está sujeita (BECK, 2011, p. 33). Ou ainda, há uma ambivalência permanente entre progresso e risco, conquista e perda, segurança e medo das novas tecnologias (NEUTZLING; ANDRADE, 2009, p. 23-24).

Dentre os inúmeros fatores críticos, a qualidade do ar atmosférico está sendo destruída pela poluição gerada pela indústria, provocando o aumento progressivo de doenças respiratórias e a diminuição das condições de se viver em grandes centros urbanos.

É no contexto da exacerbação do desenvolvimento tecnológico sem limites que, na segunda metade do século XX, inúmeros países assumiram em suas constituições o direito fundamental a viver em um ambiente ecologicamente equilibrado e à sadia qualidade de vida. A constitucionalização do meio ambiente advém de um longo período de convenções e protocolos internacionais. No Brasil, a promoção da defesa ecológica e a melhoria da sadia qualidade de vida desponta com vigor na Constituição Federal de 1988, quando o país se assume como um Estado Socioambiental de Direito alicerçado em princípios constitucionais ambientais (prevenção, poluidor-pagador, desenvolvimento sustentável, protetor-recebedor, 


\section{O MATERIAL PARTICULADO E O DIREITO À QUALIDADE DO AR [...]}

responsabilidade, solidariedade intergeracional, entre outros), delimitando claramente as responsabilidades e competências em matéria ambiental e o direito fundamental do ser humano de viver em um ambiente saudável, equilibrado, seguro e com qualidade de vida.

Vale observar que a Constituição Federal do Brasil de 1988 estabelece, em seu art. 23, inciso VI, que é competência comum da União, dos Estados, do Distrito Federal e dos Municípios a responsabilidade pela proteção do meio ambiente e combate à poluição em qualquer de suas formas. Prevê também, no parágrafo único do artigo supracitado, a fixação de normas, por meio de lei complementar, que visam ao equilíbrio do desenvolvimento e do bem-estar em âmbito nacional. No art. 24, prevê a competência concorrente da União, dos Estados e do Distrito Federal para legislar sobre a conservação da natureza, a defesa do solo e dos recursos naturais, a proteção do meio ambiente e o controle da poluição, bem como sobre a responsabilidade por dano ao meio ambiente (BRASIL, 1988).

O art. 225 da Constituição Federal de 1988, que tutela o direito ao meio ambiente, também impõe, tanto ao Poder Público quanto à coletividade, a responsabilidade pela manutenção das condições que garantam sua proteção e preservação, destacando em seu art. 225 que "todos têm direito ao meio ambiente ecologicamente equilibrado, bem de uso comum do povo e essencial à sadia qualidade de vida, impondo-se ao poder público e à coletividade o dever de defendê-lo e preservá-lo para as presentes e futuras gerações" (BRASIL, 1988). Portanto, a equidade e a solidariedade intra/intergeracional, ao se constituírem em princípio constitucional ambiental, colocam todo cidadão brasileiro como guardião do meio ambiente para as gerações presentes e vidas futuras.

Com isso, pode-se afirmar que o art. 225 da Constituição Federal é o principal núcleo normativo de proteção ambiental e, em seus incisos, elenca uma série de medidas que objetivam assegurar a efetividade do direito ao meio ambiente, sob responsabilidade do Poder Público, citando, entre elas, a preservação e a restauração dos processos ecológicos e a proteção à fauna e à flora, vedadas as práticas que coloquem em risco sua função ecológica.

Além da Constituição Federal, inúmeros diplomas infraconstitucionais tratam da questão da preservação do meio ambiente, como a Lei 6.938, de 31 de agosto de 1981, que institui a Política Nacional do Meio Ambiente e prevê, em seu artigo segundo, a intervenção governamental no sentido de assegurar o equilíbrio ecológico e o uso racional dos recursos naturais, tendo como objetivo maior a preservação do meio ambiente e visando, entre outros, à proteção da vida humana (BRASIL, 1981).

De modo exemplificativo, Sarlet e Fensterseifer (2011, p. 48-49) referem que há uma conexão entre a proteção do direito ao meio ambiente e o direito à saúde, pelo argumento R. Fac. Dir. UFG, v. 40, n.1, p. 188 - 207, jan. / jun. 2016 
de que a "saúde humana é totalmente dependente da qualidade e equilíbrio das bases naturais que dão suporte à vida" em que a ausência de condições ambientais favoráveis pode significar a violação da dignidade da pessoa humana e que a vida pode não ser mais digna de ser vivida.

$\mathrm{O}$ ar atmosférico é considerado um bem ambiental indisponível e não suscetível de apropriação, exigindo atenção especial pelo seu caráter de impactar diretamente na saúde humana. É nesse sentido que a Constituição Federal de 1988 e as legislações infraconstitucionais em questões ambientais indicam a necessidade de serem adotadas medidas preventivas e precaucionais em relação ao meio ambiente. Assim, a atuação preventiva pode ser considerada como um mecanismo de gestão de riscos, que objetiva inibir os riscos concretos ou potenciais, sendo esses visíveis e previsíveis pelo conhecimento humano (LEITE, 2012).

O princípio da prevenção considera que os danos ambientais, uma vez ocorridos, são praticamente impossíveis de serem revertidos, pois o ambiente alterado não retorna ao seu estado original após as modificações ocorridas e, em função disso, todos os cuidados devem ser observados previamente aos efeitos resultantes das atividades efetivas ou potencialmente causadoras de degradação ambiental (FIORILO, 2011; MILARÉ, 2013; ANTUNES, 2014). A este propósito, ações em matéria ambiental fundamentam-se, prioritariamente, em atender o princípio da prevenção e da reparação de danos ambientais na fonte, ou seja, em primeiro lugar deve-se "impedir a superveniência de danos ao meio ambiente por meio de medidas apropriadas, ditas preventivas, antes da elaboração de um plano ou da realização de uma obra ou atividade" (PRIEUR, 1996, p. 70).

Ressalta-se que o ar atmosférico é um macrobem e todos os esforços devem ser no sentido de prevenir a ocorrência de qualquer fato que possa causar dano ao mesmo, entre os quais o estabelecimento legal de limites para as emissões de poluentes na atmosfera e, em consequência, programas de monitoramento ambiental da qualidade do ar que objetivam avaliar a extensão da poluição, o impacto ambiental provável e a deterioração do ar. Zurita (2000) indica que essas medidas preventivas permitem avaliar a eficiência das ações mitigadoras adotadas com o objetivo de eliminar ou reduzir a origem da contaminação, observar se as normas vigentes sobre limites de emissão de poluentes estão sendo corretamente aplicadas.

Com o indicativo de que os danos ambientais na maioria das vezes são irreversíveis e irreparáveis, Fiorillo (2012, p. 126) destaca que, "desde a Conferência de Estocolmo, em 1972, o princípio da prevenção tem sido objeto de profundo apreço, içado à 


\section{O MATERIAL PARTICULADO E O DIREITO À QUALIDADE DO AR [...]}

categoria de megaprincípio do direito ambiental". Além do princípio da prevenção, a precaução também está presente como princípio na Declaração do Rio de Janeiro sobre Meio Ambiente e Desenvolvimento, de 1992, sob o número 15, o qual declara que, "com o fim de proteger o meio ambiente, o princípio da precaução deverá ser amplamente observado pelos Estados, de acordo com suas capacidades" (ONU, 2014). Atento a esse fato, o princípio da precaução estabelece que "quando houver ameaça de danos graves ou irreversíveis, a ausência de certeza científica absoluta não será utilizada como razão para o adiamento de medidas economicamente viáveis para prevenir a degradação ambiental" (ONU, 2014). Da mesma forma, de acordo com Milaré (2013, p. 265) "a incerteza científica milita em favor do ambiente, carreando-se ao interessado o ônus de provar que as intervenções pretendidas não trarão consequências indesejadas ao meio ambiente". Portanto, diante da dúvida, a decisão sempre deve ser a favor do meio ambiente e da vida.

Frente ao exposto, pode-se concluir que o meio ambiente ecologicamente equilibrado e viver com dignidade inclui também o direito ao ar de boa qualidade, em que a presença de poluentes atmosféricos seja mínima, não aportando a este, características que diminuam sua qualidade e que possam oferecer risco ao bem-estar da população. Nesse sentido, conforme destaca Milaré (2013, p. 520), “a Constituição conferiu amplíssima proteção ao ar atmosférico e, aos órgãos legalmente responsáveis, poder de controle sobre as atividades capazes de poluí-lo". Por outro lado, a poluição atmosférica cresce na sociedade de risco e se impõe como uma ameaça à civilização. Beck (2010, p. 48-49) denuncia que os venenos e poluentes estão "entrelaçados com a base natural, com a consumação elementar da vida" e que a "vivência dessa suscetibilidade ao risco interdita à escolha" e torna “compreensível muito do impacto, da ira impotente e da 'sensação de não haver amanhã'”.

Daí ser importante, alicerçando-se no princípio da solidariedade intergeracional, na vida digna, no princípio da prevenção e no princípio da precaução e no fato de que o "futuro da humanidade inclui o futuro da natureza como condição seni qua non sob o conceito chave de dever para com o homem (JONAS, 2006, p. 229)", examinar o Material Particulado (aerossol) como um dos que impactam decisivamente na poluição atmosférica e na saúde humana.

\section{MATERIAL PARTICULADO (AEROSSOL) E A POLUIÇÃO ATMOSFÉRICA}

Tecnicamente, um aerossol pode ser definido como uma suspensão de partículas sólidas ou líquidas em um gás (PANDIS; SEINFELD, 2006). Várias terminologias são R. Fac. Dir. UFG, v. 40, n.1, p. 188 - 207, jan. / jun. 2016 
usualmente empregadas para descrever as partículas atmosféricas. O termo partícula refere-se a uma única unidade do material, tendo, geralmente, uma densidade próxima da densidade do material a granel. As partículas individuais podem ser quimicamente homogêneas ou conter uma variedade de espécies químicas, podendo ser constituídas por materiais sólidos ou líquidos, ou por ambos (BARON; WILLEKE, 2001).

Muitas das terminologias empregadas na descrição dos aerossóis não têm definições científicas rigorosas, no entanto, são de uso comum, como termos meramente descritivos, frequentemente indicando a aparência ou a fonte das partículas. Os termos empregados podem também ter relação com o diâmetro da partícula $(D p)$, conforme se pode observar no Quadro 1:

Quadro 1 - Terminologia empregada na descrição de aerossóis

\begin{tabular}{|c|c|}
\hline Terminologia & Descrição \\
\hline Aerossol & Pequenas partículas dispersas em um gás. \\
\hline Poeira & $\begin{array}{l}\text { Suspensão de partículas sólidas produzidas por desintegração mecânica de materiais, } \\
\text { como britagem, moagem e explosões; } D p>1 \mu \mathrm{m} \text {. }\end{array}$ \\
\hline Névoa & $\begin{array}{l}\text { Termo vagamente aplicado para aerossóis visíveis nos quais a fase dispersa é } \\
\text { líquida; geralmente, uma dispersão de água ou gelo, próxima ao solo. }\end{array}$ \\
\hline Fumo & $\begin{array}{l}\text { Partículas sólidas geradas a partir da condensação de vapores, geralmente após } \\
\text { volatilização de substâncias fundidas, muitas vezes acompanhadas por reações } \\
\text { químicas como a oxidação; frequentemente, o material envolvido é nocivo; } D p>1 \\
\mu m \text {. }\end{array}$ \\
\hline Neblina & $\begin{array}{l}\text { Aerossol que impede a visão e pode consistir de uma combinação de gotas de água, } \\
\text { poluentes e pó; } D p<1 \mu \mathrm{m} \text {. }\end{array}$ \\
\hline Chuviscos & $\begin{array}{l}\text { Líquidos, normalmente água sob a forma de partículas suspensas na atmosfera na ou } \\
\text { perto da superfície da Terra; pequenas gotas de água flutuantes ou em queda, } \\
\text { aproximando-se à forma de chuva e, às vezes, diferenciadas das névoas por serem } \\
\text { mais transparentes ou por apresentarem partículas se movendo perceptivelmente } \\
\text { para baixo; } D p>1 \mu \mathrm{m} \text {. }\end{array}$ \\
\hline Partícula & $\begin{array}{l}\text { Pode consistir de uma única unidade de um sólido ou líquido que contém muitas } \\
\text { moléculas unidas por forças intermoleculares e, principalmente, apresentando } \\
\text { dimensões maiores do que as moleculares }(>0,001 \mu \mathrm{m}) \text {; pode também ser } \\
\text { constituída por duas ou mais dessas unidades estruturais mantidas juntas por forças } \\
\text { adesivas interpartículas, comportando-se como uma única unidade, em suspensão ou } \\
\text { em depósito. }\end{array}$ \\
\hline Smog & $\begin{array}{l}\text { Termo derivado de fumaça e neblina, aplicado à contaminação extensiva de } \\
\text { aerossóis; atualmente, por vezes, usado vagamente para qualquer contaminação do } \\
\text { ar. }\end{array}$ \\
\hline Fumaça & $\begin{array}{l}\text { Pequenas partículas gasosas resultantes de combustão incompleta, constituídas } \\
\text { predominantemente por carbono e outros materiais combustíveis, e presentes em } \\
\text { quantidade suficiente para ser observável, independentemente da presença de outros } \\
\text { sólidos. } D p \geq 0,01 \mu \mathrm{m} \text {. }\end{array}$ \\
\hline Fuligem & $\begin{array}{l}\text { Aglomerações de partículas de carbono impregnadas com "alcatrão", formadas na } \\
\text { combustão incompleta de material carbonáceo. }\end{array}$ \\
\hline
\end{tabular}

Fonte: Adaptado de PANDIS; SEINFELD, 2006; BARON; WILLEKE, 2001; MANAHAN, 2000. 


\section{O MATERIAL PARTICULADO E O DIREITO À QUALIDADE DO AR [...]}

O termo material particulado engloba as definições do Quadro 1 e é empregado de forma genérica para designar um tipo de poluição atmosférica presente no ar, em ambientes urbanos e não urbanos, que consiste em misturas complexas de diversos componentes, constituído por partículas sólidas e líquidas em suspensão, cujo diâmetro e composição variam, uma vez que podem absorver e transferir uma grande diversidade de poluentes (CASTANAS; KAMPA, 2008). O material particulado é a forma mais visível de poluição atmosférica, sendo as partículas com diâmetro entre 0,001 a $10 \mu \mathrm{m}$ comumente encontradas suspensas no ar, próximas as suas fontes de emissão, como as plantas industriais, rodovias e usinas termoelétricas, assim como na atmosfera de áreas urbanas (MANAHAN, 2000).

O material particulado é classificado em função de seu diâmetro aerodinâmico, em material particulado grosso e fino, visto que sua composição química está diretamente associada ao tamanho das partículas e, consequentemente, em seu potencial de degradação, bem como em seu local de deposição, tanto no que se refere ao meio ambiente, quanto nos organismos vivos. $\mathrm{O}$ material particulado grosso $\left(\mathrm{MP}_{10}\right)$ ou material particulado inalável, composto por partículas com diâmetro aerodinâmico menor que $10 \mu \mathrm{m}$, é capaz de penetrar no sistema respiratório humano, provocando o aumento de doenças. Uma vez que a inalação é a principal via de exposição humana a substâncias químicas presentes no ar, todas as informações obtidas referentes à composição química das amostras de material particulado contribuem para a avaliação de possíveis riscos ambientais.

As partículas maiores, que constituem o material particulado grosso, na grande maioria das vezes, são produzidas mecanicamente pelo fracionamento de partículas sólidas maiores. Assim, nas áreas urbanas, as partículas grossas geralmente contêm poeira em ressuspensão, materiais provenientes das atividades industriais e material biológico, como grãos de pólen e fragmentos de bactérias. A composição das partículas grossas também inclui materiais da crosta terrestre transportados pelo vento, proveniente de atividades agrícolas, de solos descobertos, estradas não pavimentadas ou operações de mineração. Em regiões costeiras, a evaporação da água do mar também pode produzir partículas grossas. Podem também ser formadas a partir da liberação de materiais não combustíveis em processos de combustão, ou seja, as cinzas (WHO, 2006). Segundo Castanas e Kampa (2008), os principais componentes do Material Particulado são metais, compostos orgânicos, íons, gases reativos e materiais carbonáceos, sendo o conteúdo metálico, a presença de hidrocarbonetos policíclicos aromáticos (HPA's) e entre outros componentes orgânicos, importantes contribuintes para o aumento de sua toxicidade. 
As partículas menores, ou seja, o material particulado fino $\left(\mathrm{MP}_{2,5}\right)$, aquele constituído por partículas de diâmetro aerodinâmico menor que 2,5 $\mu \mathrm{m}$, é, em grande parte, formado a partir de gases, mas os processos de combustão podem também gerar partículas primárias na fração fina. Tipicamente, essas partículas têm origem nas partículas ultrafinas produzidas por nucleação-condensação de substâncias de baixa pressão de vapor, formadas por vaporização a altas temperaturas ou por reações químicas na atmosfera. Estas podem aumentar de tamanho por processos de coagulação (a combinação de duas ou mais partículas para formar uma partícula maior) ou por condensação de moléculas de gás ou vapor sobre a superfície de partículas existentes (WHO, 2006).

O material particulado fino apresenta maior potencial para o desenvolvimento de efeitos adversos, uma vez que este diâmetro possibilita que as partículas, quando inaladas, alcancem com facilidade os alvéolos pulmonares, enquanto que as partículas com diâmetro maior ficam retidas nas vias superiores do trato respiratório, o que reduz consideravelmente seus efeitos nocivos. Além disso, a fração fina do material particulado tem como principal origem as fontes antrópicas (emissões industriais e as resultantes da queima de combustíveis) e corresponde à fração na qual normalmente estão acumulados metais pesados como níquel, cádmio e outras substâncias tóxicas, o que agrava ainda mais os riscos potenciais dessa fração de partículas (ESPINOSA et al., 2001; HIEU; LEE, 2010; TEIXEIRA et al., 2011). A exposição a poluentes atmosféricos como o material particulado pode ocasionar o aumento da incidência de, pelo menos, dois grupos de efeitos adversos à saúde: doenças respiratórias e cardiovasculares. Os efeitos podem ser consequência de exposições agudas ou crônicas, tendo sido relatados por muitos pesquisadores em vários países (DOCKERY et al., 1999; POPE III, 2000; FORTIet al., 2007; LAUPELE et al., 2012).

É fácil perceber que os efeitos dos materiais particulados sobre a saúde humana e o meio ambiente estão em desacordo com os deveres fundamentais insculpidos no art. 225 da Constituição Federal. Um dos aspectos mais impactantes é que a poluição ocasionada pelo material particulado constrói vínculos negativos com o futuro em que não é possível identificar todos os efeitos para as gerações presentes e futuras.

\section{A LESGILAÇÃO NACIONAL E INTERNACIONAL SOBRE MATERIAL PARTICULADO}

\subsection{Legislação Brasileira sobre Material Particulado}




\section{O MATERIAL PARTICULADO E O DIREITO À QUALIDADE DO AR [...]}

Em 1989, o Conselho Nacional do Meio Ambiente (CONAMA), considerando questões relacionadas com a aceleração do crescimento urbano e industrial brasileiro, o crescimento da frota de veículos automotores, o aumento dos índices de poluição atmosférica e seus impactos negativos nas atividades sociais, econômicas e sobre o meio ambiente, publicou a Resolução CONAMA n ${ }^{\circ}$, de 15 de junho de 1989, que instituiu o Programa Nacional de Controle da Poluição do Ar (PRONAR) (BRASIL, 1989).

O PRONAR se caracterizou como um instrumento de gestão ambiental, limitando os níveis de emissão de poluentes por fontes de emissão, com vistas a preservar a qualidade do ar em ambientes já afetados e evitar o comprometimento da qualidade do ar em áreas não degradadas ou afetadas pela ação antrópica. Como ferramentas do programa, o CONAMA previu a adoção de limites máximos de emissão de poluentes a serem lançados pelas fontes de emissão, bem como a classificação das diferentes áreas do território nacional em função dos usos pretendidos e a diferenciação dos limites de emissão em função da classificação. Dessa forma, nas áreas nas quais a qualidade do ar não tenha sofrido danos em função da ação antrópica, os limites de emissão seriam mais restritivos, ao passo que as áreas urbanizadas ou industrializadas seriam enquadradas em limites menos restritivos, flexibilizando o desenvolvimento socioeconômico dessas áreas (BRASIL, 1989).

A Resolução CONAMA no 5/89 estabeleceu dois padrões para avaliação da qualidade do ar: o padrão primário, ou seja, o nível máximo tolerável de concentração de determinado poluente atmosférico que, se ultrapassado, pode afetar desfavoravelmente a saúde e o bem-estar da população, e o padrão secundário, podendo ser entendido como o nível de concentração de um poluente específico abaixo do qual os efeitos adversos sobre o bemestar da população e os danos ao meio ambiente sejam mínimos (BRASIL, 1989).

Posteriormente, na Resolução CONAMA nº 3, de 28 de junho de 1990, foram estabelecidos os Padrões Nacionais de Qualidade do Ar, em que constam os poluentes a serem monitorados pelos Estados, sendo eles: Partículas Totais em Suspensão (PTS), Fumaça, Partículas Inaláveis (PI), Dióxido de Enxofre $\left(\mathrm{SO}_{2}\right)$, Monóxido de Carbono (CO), Ozônio $\left(\mathrm{O}_{3}\right)$ e Dióxido de Nitrogênio $\left(\mathrm{NO}_{2}\right)$. No que diz respeito ao material particulado, estabelece padrões para as Partículas Totais em Suspensão (PTS) e para as Partículas Inaláveis $\left(\mathrm{MP}_{10}\right)$, que corresponde à fração grossa do material particulado, conforme Tabela 1: 
Haide Maria Hupffer, André Rafael Weyermüller e Darlan Daniel Alves

\section{Tabela 1 - Padrões para Partículas Totais em Suspensão e Material Particulado Inalável, conforme Resolução CONAMA nº 3/90}

\begin{tabular}{|c|c|c|c|c|}
\hline Poluente & $\begin{array}{c}\text { Primário } \\
\text { /Secundário }\end{array}$ & $\begin{array}{c}\text { Média de } \\
\text { Tempo }\end{array}$ & Padrão & Forma \\
\hline \multirow{4}{*}{ PTS } & \multirow{2}{*}{ Primário } & Anual & $80 \mu \mathrm{g} / \mathrm{m}^{3}$ & $\begin{array}{l}\text { Concentração média geométrica } \\
\text { anual }\end{array}$ \\
\hline & & 24 horas & $240 \mu \mathrm{g} / \mathrm{m}^{3}$ & $\begin{array}{l}\text { Não deve ser excedida mais de } \\
\text { uma vez por ano }\end{array}$ \\
\hline & \multirow{2}{*}{ Secundário } & Anual & $60 \mu \mathrm{g} / \mathrm{m}^{3}$ & $\begin{array}{c}\text { Concentração média geométrica } \\
\text { anual }\end{array}$ \\
\hline & & 24 horas & $150 \mu \mathrm{g} / \mathrm{m}^{3}$ & $\begin{array}{c}\text { Não deve ser excedida mais de } \\
\text { uma vez por ano }\end{array}$ \\
\hline \multirow{2}{*}{$\begin{array}{l}\text { Partículas } \\
\text { Inaláveis } \\
\left(\mathrm{MP}_{10}\right)\end{array}$} & \multirow{2}{*}{$\begin{array}{l}\text { Primário e } \\
\text { Secundário }\end{array}$} & Annual & $50 \mu \mathrm{g} / \mathrm{m}^{3}$ & $\begin{array}{c}\text { Concentração média aritmética } \\
\text { anual }\end{array}$ \\
\hline & & 24 horas & $150 \mu \mathrm{g} / \mathrm{m}^{3}$ & $\begin{array}{l}\text { Não deve ser excedida mais de } \\
\text { uma vez por ano }\end{array}$ \\
\hline
\end{tabular}

Fonte: Adaptado de BRASIL, 1990.

Ainda em 1990, a Resolução CONAMA n 5 foi complementada pela Resolução CONAMA $\mathrm{n}^{\circ}$ 08, dispondo, sobre o estabelecimento de limites máximos de emissão de poluentes no ar para processos de combustão externa de fontes fixas. Em 2011, foi complementada pela Resolução CONAMA nº 436, a qual estabeleceu limites máximos de emissão de poluentes atmosféricos para fontes fixas instaladas ou com pedido de licença de instalação anteriores a 2 de janeiro de 2007.

Dessa forma, têm-se os dispositivos elaborados pelo CONAMA e que estabelecem os Padrões Nacionais de Qualidade do Ar, bem como os limites máximos permitidos para emissão de poluentes por parte do setor industrial, cujo objetivo principal é a proteção e a garantia da qualidade do ar para as gerações presentes e futuras. Ademais, registra-se que os mesmos estão em sintonia com o princípio da prevenção e com o art. 225 da Constituição Federal. O que se pode questionar é a efetividade de mecanismo de monitoramento sistemático de fiscalização dos limites máximos de emissão e as condições de lançamento de poluentes atmosféricos, bem como se a forte carga preventiva prevista para a proteção da qualidade do ar na legislação constitucional e infraconsticional é realmente observada.

\subsection{Legislação Norte-Americana sobre Material Particulado}

Em 1970, o Congresso dos Estados Unidos da América estabeleceu grande parte da estrutura de sua política de preservação da qualidade do ar na Política do Ar Limpo (Clean 


\section{O MATERIAL PARTICULADO E O DIREITO À QUALIDADE DO AR [...]}

Air Act), o qual foi revisado em 1977 e 1990. As revisões foram elaboradas no sentido de melhorar sua eficácia e contemplar problemas recentes de poluição atmosférica, como a chuva ácida e danos à camada de ozônio estratosférico (EPA, 2014a).

A partir de 1971, o parâmetro Material Particulado teve alterações, tanto no que se refere aos níveis, os quais foram gradativamente diminuindo, tornando-se cada vez mais restritivos, bem como no tipo de material a ser considerado como objeto de amostragem, partindo-se de uma legislação que previa somente o parâmetro Partículas Totais em Suspensão em 1971, e evoluindo para uma legislação que prevê, atualmente, o monitoramento dos parâmetros $\mathrm{MP}_{10}$ e $\mathrm{MP}_{2,5}$, unicamente. Essas alterações ocorreram no sentido de melhorar a eficácia da lei e também para minimizar os problemas de poluição do ar recentemente reconhecidos, como a chuva ácida e os danos à camada de ozônio estratosférico (EPA, 2014a).

Obviamente, existe uma forte relação entre as alterações legislativas norteamericanas com os avanços científicos, em que se percebe que a legislação é alterada no sentido de se adequar às necessidades atuais, tendo como base os resultados divulgados no meio científico. Isso fica bastante claro quando se observa a evolução dos padrões e parâmetros empregados para monitoramento no Material Particulado nos diplomas legais norte-americanos (Tabela 2):

Tabela 2 - Histórico das Alterações nos Padrões Nacionais Ambientais de Qualidade do Ar para Material Particulado, 1971 a 2012

\begin{tabular}{|c|c|c|c|c|c|}
\hline Ano & $\begin{array}{l}\text { Primário/Se } \\
\text { cundário }\end{array}$ & Parâmetro & Tempo & Padrão & Forma \\
\hline \multirow{3}{*}{1971} & \multirow[t]{2}{*}{ Primário } & \multirow{3}{*}{ PTS } & 24 horas & $260 \mu \mathrm{g} / \mathrm{m}^{3}$ & $\begin{array}{l}\text { Não deve exceder mais de uma vez } \\
\text { por ano } \\
\end{array}$ \\
\hline & & & Annual & $75 \mu \mathrm{g} / \mathrm{m}^{3}$ & Média anual \\
\hline & Secundário & & 24 horas & $150 \mu \mathrm{g} / \mathrm{m}^{3}$ & $\begin{array}{l}\text { Não deve exceder mais de uma vez } \\
\text { por ano }\end{array}$ \\
\hline \multirow[t]{2}{*}{1987} & \multirow{2}{*}{$\begin{array}{l}\text { Primário e } \\
\text { Secundário }\end{array}$} & \multirow[t]{2}{*}{$\mathrm{MP}_{10}$} & 24 horas & $150 \mu \mathrm{g} / \mathrm{m}^{3}$ & $\begin{array}{c}\text { Não deve ser excedido mais de uma } \\
\text { vez por ano, em média, ao longo de } \\
\text { um período de } 3 \text { anos }\end{array}$ \\
\hline & & & Anual & $50 \mu \mathrm{g} / \mathrm{m}^{3}$ & $\begin{array}{l}\text { Média aritmética anual, média de e } \\
\text { anos }\end{array}$ \\
\hline \multirow{4}{*}{1997} & \multirow{4}{*}{$\begin{array}{l}\text { Primário e } \\
\text { Secundário }\end{array}$} & \multirow[b]{2}{*}{$\mathrm{MP}_{2,5}$} & 24 horas & $65 \mu \mathrm{g} / \mathrm{m}^{3}$ & $98^{\circ}$ percentil, média de 3 anos \\
\hline & & & Anual & $15,0 \mu \mathrm{g} / \mathrm{m}^{3}$ & $\begin{array}{l}\text { Média aritmética anual, média de } 3 \\
\operatorname{anos}_{(1),(2)}\end{array}$ \\
\hline & & & & & $\begin{array}{l}\text { Inicialmente promulgado o } 99^{\circ} \\
\text { percentil, média dos } 3 \text { últimos anos; } \\
\text { quando os padrões de } 1997 \text { para }\end{array}$ \\
\hline & & $\mathrm{MP}_{10}$ & 24 horas & $150 \mu \mathrm{g} / \mathrm{m}^{3}$ & $\begin{array}{l}\mathrm{PM}_{10} \text { foram abandonados, a forma } \\
\text { dos padrões de } 1987 \text { permaneceu no } \\
\text { local (não deve ser excedido mais de } \\
\text { uma vez por ano, em média, ao longo }\end{array}$ \\
\hline
\end{tabular}


Haide Maria Hupffer, André Rafael Weyermüller e Darlan Daniel Alves

\begin{tabular}{|c|c|c|c|c|c|}
\hline & & & & & de um período de 3 anos) \\
\hline & & & Anual & $50 \mu \mathrm{g} / \mathrm{m}^{3}$ & $\begin{array}{l}\text { Média aritmética anual, média de } 3 \\
\text { anos }\end{array}$ \\
\hline \multirow{3}{*}{2006} & \multirow{3}{*}{$\begin{array}{l}\text { Primário e } \\
\text { Secundário }\end{array}$} & \multirow[b]{2}{*}{$\mathrm{MP}_{2,5}$} & 24 horas & $35 \mu \mathrm{g} / \mathrm{m}^{3}$ & $98^{\circ}$ percentil, média de $3 \operatorname{anos}^{(3)}$ \\
\hline & & & Anual & $15 \mu \mathrm{g} / \mathrm{m}^{3}$ & $\begin{array}{l}\text { Média aritmética anual, média de } 3 \\
\text { anos }\end{array}$ \\
\hline & & $\mathrm{MP}_{10}$ & $\begin{array}{c}24 \\
\text { horas }^{(4)}\end{array}$ & $150 \mu \mathrm{g} / \mathrm{m}^{3}$ & $\begin{array}{c}\text { Não deve ser excedido mais de uma } \\
\text { vez por ano, em média, ao longo de } \\
\text { um período de } 3 \text { anos }\end{array}$ \\
\hline \multirow{4}{*}{2012} & Primário & \multirow{3}{*}{$\mathrm{MP}_{2,5}$} & Anual & $12 \mu \mathrm{g} / \mathrm{m}^{3}$ & $\begin{array}{l}\text { Média aritmética anual, média de } 3 \\
\text { anos }\end{array}$ \\
\hline & Secundário & & Anual & $15,0 \mu \mathrm{g} / \mathrm{m}^{3}$ & $\begin{array}{l}\text { Média aritmética anual, média de } 3 \\
\text { anos }\end{array}$ \\
\hline & $\begin{array}{l}\text { Primário e } \\
\text { Secundário }\end{array}$ & & 24 horas & $35 \mu \mathrm{g} / \mathrm{m}^{3}$ & $98^{\circ}$ percentil, média de 3 anos ${ }^{(3)}$ \\
\hline & $\begin{array}{l}\text { Primário e } \\
\text { Secundário }\end{array}$ & $\mathrm{MP}_{10}$ & $\begin{array}{c}24 \\
\text { horas }^{(4)}\end{array}$ & $150 \mu \mathrm{g} / \mathrm{m}^{3}$ & $\begin{array}{l}\text { Não deve ser excedido mais de uma } \\
\text { vez por ano, em média, ao longo de } \\
\text { um período de } 3 \text { anos }\end{array}$ \\
\hline
\end{tabular}

${ }^{(1)} \mathrm{O}$ nível da média anual é definido por uma casa decimal (por exemplo, $15,0 \mu \mathrm{g} / \mathrm{m}^{3}$ ), conforme determinado pelo arredondamento. Por exemplo, uma média anual de 3 anos de $15,04 \mu \mathrm{g} / \mathrm{m}^{3}$ seria arredondada para $15,0 \mu \mathrm{g} / \mathrm{m}^{3}$ e, então se enquadraria ao padrão anual e, uma média anual de e 3 anos de $15,05 \mu \mathrm{g} / \mathrm{m}^{3}$ seria arredondada para $15,1 \mu \mathrm{g} / \mathrm{m}^{3}$ e, consequentemente, violaria o padrão anual.

${ }^{(2)} \mathrm{O}$ nível do padrão deve ser comparado com as medições feitas em locais que representam a "qualidade do ar em toda a comunidade", registrando o nível mais alto, ou, se requerimentos específicos forem atendidos, para ratear medições de vários locais de monitoramento que representam a "qualidade do ar em toda a comunidade".

${ }^{(3)} \mathrm{O}$ nível do padrão de 24 horas é definido como um número inteiro (nenhuma casa decimal), determinado pela média. Por exemplo, o $98^{\circ}$ percentil de uma média da concentração de 3 anos de 35,49 $\mu \mathrm{g} / \mathrm{m}^{3}$ seria arredondada para $35 \mu \mathrm{g} / \mathrm{m}^{3}$ e, então, atenderia o padrão de 24 horas e uma média de 3 anos de $35,50 \mu \mathrm{g} / \mathrm{m}^{3}$ seria arredondada para $36 \mu \mathrm{g} / \mathrm{m}^{3}$ e, consequentemente, violaria o padrão de 24 horas.

${ }^{(4)}$ A EPA revogou em 2006 o padrão anual de $\mathrm{PM}_{10}$ nos Padrões Nacionais Ambientais de Qualidade do Ar.

Fonte: Adaptado de EPA, 2014c

A partir do estabelecido na Política do Ar Limpo, a Agência de Proteção Ambiental dos Estados Unidos (United States Environment Protection Agency) ou simplesmente EPA, órgão ambiental norte-americano, elaborou o documento intitulado Padrões Ambientais Nacionais de Qualidade do Ar (National Ambient Air Quality Standards), documento que elencaria os poluentes considerados nocivos à saúde pública e ao meio ambiente. Os Padrões Ambientais Nacionais de Qualidade do Ar norte-americanos, assim como ocorre no Brasil, identificam dois tipos de padrões de qualidade do ar: o padrão primário e o padrão secundário. Os padrões primários proporcionam proteção da saúde pública, incluindo a proteção da saúde das populações "sensíveis", como os asmáticos, crianças e idosos. Os padrões secundários proporcionam proteção do bem-estar público, incluindo a proteção contra a diminuição da visibilidade e danos aos animais, colheitas, vegetação e construções (EPA, 2014b). 
A EPA estabeleceu padrões para seis poluentes principais: o Monóxido de Carbono (CO), Chumbo $(\mathrm{Pb})$, Dióxido de Nitrogênio $\left(\mathrm{NO}_{2}\right)$, Ozônio $\left(\mathrm{O}_{3}\right)$, Material Particulado (MP) e Dióxido de Enxofre $\left(\mathrm{SO}_{2}\right)$. No caso específico do material particulado, considera como parâmetros a fração fina e grossa desse poluente, definindo critérios, níveis e formas de avaliação para os padrões primário e secundário, conforme Tabela 3:

Tabela 3-Padrões Para Material Particulado Grosso $\left(\mathbf{P M}_{10}\right)$ e Fino $\left(\mathbf{M P}_{2,5}\right)$, conforme EPA

\begin{tabular}{ccccc}
\hline Poluente & $\begin{array}{c}\text { Primário/Secund } \\
\text { ário }\end{array}$ & $\begin{array}{c}\text { Média de } \\
\text { Tempo }\end{array}$ & Padrão & Forma \\
\cline { 2 - 5 } $\mathrm{MP}_{2,5}$ & Primário & Anual & $12 \mu \mathrm{g} / \mathrm{m}^{3}$ & $\begin{array}{c}\text { Média anual, média dos 3 últimos } \\
\text { anos }\end{array}$ \\
\cline { 2 - 5 } & $\begin{array}{c}\text { Secundário } \\
\text { Primário e }\end{array}$ & Anual & $15 \mu \mathrm{g} / \mathrm{m}^{3}$ & $\begin{array}{c}\text { Média anual, média dos } 3 \text { últimos } \\
\text { anos }\end{array}$ \\
\hline $\mathrm{MP}_{10}$ & $\begin{array}{c}\text { Primário e } \\
\text { Secundário }\end{array}$ & 24 horas & $35 \mu \mathrm{g} / \mathrm{m}^{3}$ & $98^{\circ}$ percentil, média de 3 anos \\
\hline
\end{tabular}

Fonte: EPA, 2014b

Atualmente, a legislação norte-americana considera como objeto de monitoramento, para fins de atendimento do previsto em seus Padrões Ambientais Nacionais de Qualidade do $\mathrm{Ar}$, as frações grossa $\left(\mathrm{MP}_{10}\right)$ e fina $\left(\mathrm{MP}_{2,5}\right)$ do material particulado, não considerando as Partículas Totais em Suspensão, como ocorre na legislação brasileira.

\section{CONCLUSÃO}

O direito à qualidade do ar está associado aos interesses transindividuais, uma vez que se trata de um bem de interesse coletivo, protegido pelos direitos difusos. O princípio da solidariedade intergeracional, esculpido no art. 225 da Constituição Federal, guarda estreita relação com os princípios da prevenção, da precaução, do desenvolvimento sustentável e da dignidade da pessoa humana. A qualidade do ar atmosférico é indispensável para que o ser humano viva com dignidade. Por isso, a Organização Mundial da Saúde (OMS) recomenda limites máximos de concentração de alguns poluentes presentes na atmosfera.

Por meio dos Padrões Ambientais Nacionais de Qualidade do Ar, a legislação norte-americana passou a considerar, desde 1997, o parâmetro Material Particulado fino $\left(\mathrm{MP}_{2,5}\right)$ como objeto de monitoramento e avaliação da qualidade do ar. A seleção desse poluente para compor o rol dos parâmetros monitorados é bastante acertada, visto que, conforme discutido neste estudo, a fração fina do material particulado é considerada por R. Fac. Dir. UFG, v. 40, n.1, p. 188 - 207, jan. /jun. 2016 
muitos pesquisadores como a mais impactante, pois é responsável pelo acúmulo e transporte de uma gama de metais pesados e outras substâncias tóxicas. Além disso, apresenta elevado potencial de assimilação pelo homem, pois, quando inaladas, percorrem o trato respiratório, alcançando os alvéolos pulmonares com maior facilidade.

A legislação brasileira não considera o Material Particulado fino em seus diplomas legais de proteção ao meio ambiente, distanciando-se enormemente da legislação norte-americana. Nesse item, percebe-se um sincronismo entre os critérios adotados pelas autoridades norte-americanas para promover a qualidade ambiental e os resultados dos trabalhos publicados por pesquisadores da área ambiental. Não há sombra de dúvida de que os resultados obtidos em pesquisas científicas devam servir como instrumento norteador na elaboração e atualização de leis e de políticas públicas que objetivem a proteção e a preservação ambiental.

Ao se analisar a legislação brasileira vigente, verifica-se que esta considera os parâmetros Partículas Totais em Suspensão (PTS) e as Partículas Inaláveis ou Material Particulado grosso $\left(\mathrm{PM}_{10}\right)$ como objetos de monitoramento e avaliação da qualidade ambiental. Na análise das duas legislações, percebe-se que o Material Particulado grosso $\left(\mathrm{MP}_{10}\right)$ e seus padrões presentes na legislação brasileira são exatamente iguais ao determinado pelo órgão ambiental norte-americano em seus diplomas, datados de 1987. Cabe ressaltar que esses números já foram revistos pelo órgão ambiental daquele país após o ano de 1987, passando por revisões nos anos de 1997, 2006 e 2012, quando se tornaram ainda mais restritivos, o que equivale a dizer que passaram a contribuir de forma ainda mais efetiva para a proteção da qualidade ambiental. Com relação ao parâmetro Partículas Totais em Suspensão (PTS), este foi excluído do rol de parâmetros dos Padrões Ambientais de Qualidade do Ar norte-americanos a partir de 1987.

Ressalta-se, então, a importância da realização de uma análise crítica dos parâmetros de monitoramento e avaliação da qualidade do ar nas leis brasileiras, a fim de se verificar sua eficácia. Ainda, considerando a existência de estudos científicos que indicam a importância do monitoramento e avaliação das partículas finas do material particulado e a necessidade de se estabelecer efetivamente o princípio da prevenção, objetivando um meio ambiente ecologicamente equilibrado, torna-se evidente a necessidade de reformulação dos parâmetros e padrões adotados pelo órgão ambiental brasileiro, a fim de que esses possam assegurar condições saudáveis para o desenvolvimento de uma sociedade que tem como um de seus pilares o meio ambiente ecologicamente equilibrado. 
ANTUNES, Paulo de Bessa. Direito Ambiental. 16. ed. São Paulo: Atlas, 2014.

BARON, P. A.; WILLEKE, K. Aerosol Measurement: principles, techniques, and applications. 2. Ed. New York: John Wiley\& Sons, 2001.

BECK, U. Risk Society: towards a new modernity. Sage Publications. Great Britain, 1992. La Sociedad del riesgo: hacia una nueva modernidad. Tradução de Jorge Navarro, Daniel Jiménez e Maria Rosa Borrás. Barcelona: Paidós, 1998.

Paidós, 2007.

La Sociedade del riesgo mundial: en busca de la seguridad perdida. Barcelona: Socidade de risco - Rumo a uma outra modernidade. Traduzido por Sebastian Nascimento. São Paulo: Ed. 34, 2010. 2011.

BRASIL. Lei $\mathbf{n}^{0} \mathbf{6 . 9 3 8}$, de 31 de agosto de 1981. Disponível em: <http://www.planalto.gov.br/ccivil_03/leis/16938.htm > Acesso em: 20 jun. 2014.

BRASIL. Ministério do Meio Ambiente. Resolução CONAMA no 3, de 28 de junho de 1990. Disponível em: <http://www.mma.gov.br/port/conama/legiabre.cfm?codlegi=100> Acesso em: 20 jun. 2014.

BRASIL. Ministério do Meio Ambiente. Resolução CONAMA no 5, de 15 de junho de 1989. Disponível em: <http://www.mma.gov.br/port/conama/res/res89/res0589.html > Acesso em: 23 jun. 2014.

BRASIL. Ministério do Meio Ambiente. Resolução CONAMA n 8, de 6 de dezembro de 1990. Disponível em: <http://www.mma.gov.br/port/conama/legiabre.cfm?codlegi=105> Acesso em: 23 jun. 2014.

BRASIL. Ministério do Meio Ambiente. Resolução CONAMA n 436, de 22 de dezembro de 2011. Disponível em: 〈http://www.mma.gov.br/port/conama/legiabre.cfm?codlegi=660> Acesso em: 23 jun. 2014.

MILARÉ, E. Direito do Ambiente. 8. ed. São Paulo: Revista dos Tribunais, 2013.

BRASIL. Senado Federal. Constituição da República Federativa do Brasil, 5 de outubro de $1988 . \quad$ Disponível em: <http://www.planalto.gov.br/ccivil_03/constituicao/constituicao.htm> Acesso em: 19 jun. 2014.

CANOTILHO, J. G.; LEITE, J. R. M. Direito constitucional ambiental brasileiro. 5 ed. São Paulo: Editora Saraiva, 2012.

CASTANAS, E.; KAMPA, M. Human health effects of air pollution. Environmental Pollution, v. 151, n. 2, p. 362-367, 2008.

COUTINHO, F. S. da N. Direito Ambiental. O meio ambiente e os desafios da Contemporaneidade. Editora Forum. Belo Horizonte. 2010. 
DOCKERY, D. W.et al. Fine particle and peak flow in children: acidity versus mass. Epidemiology, v. 10, n. 5, p. 550-553, 1999.

ENVIRONMENT PROTECTION AGENCY (EPA). Clean Air Act Requirements and History. Disponível em: <http://www.epa.gov/air/caa/requirements.html> Acesso em: 16 jun. 2014a.

ENVIRONMENT PROTECTION AGENCY (EPA). National Ambient Air Quality Standards (NAAQS). Disponível em: <http://www.epa.gov/air/criteria.html> Acesso em: 16 206 jun. 2014b.

ENVIRONMENT PROTECTION AGENCY (EPA). Particulate Matter (PM) Standards Table of Historical PM NAAQS. Disponível em: <http://www.epa.gov/ttn/naaqs/standards/pm/s_pm_history.html> Acesso em: 16 jun. 2014c.

ESPINOSA, A. J. F. et al.Size distribution of metals in urban aerosols in Seville (Spain). Atmospheric Environment,v. 35, n. 2, p. 2595-2601, 2001.

FIORILO, C. A. P.Curso de direito ambiental brasileiro. 12. ed.São Paulo: Editora Saraiva, 2011.

FORTI, M. C. et al. Association between ionic composition of fine and coarse aerosolsoluble fraction and peak expiratory flow of asthmatic patientsin São Paulo city (Brazil). AtmosphericEnvironment, v. 41 p. 2036-2048, 2007.

HIEU, N. T.; LEE, B. K. Characteristics of particulate matter and metals in the ambient air from a residential area in the largest industrial city in Korea. Atmospheric Research, v. 98, n. 2-4, p. 526-537, 2010.

JONAS, H. O princípio responsabilidade - Ensaio de uma ética para a civilização tecnológica. Traduzido por Marijane Lisboa e Luiz Barros Montez. Rio de Janeiro: Contraponto; Ed. PUC-Rio, 2006.

LAUPELE, J. et al.Chronic Exposure to Fine ParticlesandMortality: AnExtended Follow-up ofthe Harvard SixCities Study from 1974 to 2009. Environmental Health Perspectives, v. 120, n. 7, p. 965-970, 2012.

LEITE, J. R. M. Sociedade de Risco e Estado. In: CANOTILHO, J. G.; LEITE, J. R. M. Direito constitucional ambiental brasileiro. 5. ed. São Paulo: Saraiva, 2012.

MANAHAN, S. E. Environmental Science, Technology, and Chemistry. Environmental Chemistry. 7 ed.Florida: CRC Press LLC, 2000.

MILARÉ, Édis. Direito do Ambiente. 8. ed. rev. atual. e reform. São Paulo: Editora Revista dos Tribunais, 2013.

NEUTZLING, Inácio; ANDRADE, Paulo Fernando Carneiro de. Uma sociedade PósHumana. São Leopoldo: EdUNISINOS, 2009.

PRIEUR, Michel. Droit de L'Invironnement. Paris: Dalloz, 1996, p. 70.

R. Fac. Dir. UFG, v. 40, n.1, p. 188 - 207, jan. / jun. 2016

ISSN 0101-7187 
O MATERIAL PARTICULADO E O DIREITO À QUALIDADE DO AR [...]

ORGANIZAÇÃO DAS NAÇÕES UNIDAS (ONU). Declaração do Rio sobre Meio Ambiente e Desenvolvimento. Disponível em: <http://www.onu.org.br/rio20/img/2012/01/rio92.pdf> Acesso em: 23 jun. 2014.

OST, François. A natureza à margem da Lei: a ecologia à prova do Direito. Lisboa: Instituto Piaget, 1997.

POPE III, C. A. Epidemiologyof Fine Particulate Air PollutionandHuman Health:

BiologicMechanisms and Who's at Risk? Environmental Health Perspectives, v. 108, n. 4, p. 713- 723, 2000.

PANDIS, S. N.;SEINFELD, J. H. Atmospheric chemistry and physics: from air pollution to climate change. 2. ed. New York: John Wiley \& Sons, 2006.

SARLET, I. W.; FENSTERSEIFER, T. Direito Constitucional Ambiental - Estudos sobre a Constituição, os Direitos Fundamentais e a Proteção do Ambiente. São Paulo: Editora Revista dos Tribunais, 2011.

TEIXEIRA, E. C. et al. Study of nitro-polycyclic aromatic hydrocarbons in fine and coarseatmospheric particles. Atmospheric Research, v. 101, n. 3, p. 631-639, 2011.

WORLD HEALTH ORGANIZATION (WHO).Air quality guidelines: global update 2005. Copenhagen, 2006.

ZURITA, M. L. L; et al. Qualidade do Ar em Porto Alegre. Porto Alegre: Secretaria Municipal de Meio Ambiente, 2000.

Artigo recebido em 21 de setembro de 2014 e aceito em 20 de junho de 2015 